\title{
Construction \& Standardization of Anger Scale: Validation with the help of EEG
}

\author{
Shraddha Sharma ${ }^{1}$, Ira Das ${ }^{2}$
}

\section{ABSTRACT}

Anger is a natural emotion which involves a strong uncomfortable and emotional response to a perceived provocation. Mild anger motivates an individual to take appropriate action in many areas of life. When anger goes beyond an optimal level it not only causes physical harm and psychological harm but it also intrudes with achievement of higher level of consciousness. In order to measure and compare anger among individuals a need for construction of anger scale was realized. Therefore, the researcher tried to construct a scale which could measure anger among individuals. Items with low coefficient of correlation ( $r=.14$ or less) were discarded and finally 30 items with $r=.15$ to .67 were retained in the final test. Thus, internal consistency of Anger Scale was established. Test Retest Reliability of the scale (with a time gap of 25 days) came out to be .86. For establishing criterion validity, scores on Anger Scale were correlated with scores of well being. High negative coefficient of correlation of anger scores with well being indicated that higher the anger lower is the level of well being among individuals. The coefficient of correlation was found to be -.85. Again criterion validity was supported by significant positive relationship between egotism and anger also. The coefficient of correlation was .65. It shows that as the egotism increases the level of anger increases and vice versa. Validity of anger scale was established with the help of scores on EEG. The mean alpha waves of higher anger group were found to decrease significantly when subjects' anger was experimentally aroused. On the other hand Mean EEG scores of low anger group as measured by the Anger Scale did not change significantly. Thus, the validity of anger scale was experimentally established.

Keywords: Construction, Standardization, Anger Scale, EEG

"Holding on Anger is like grasping a hot coal with the intent of throwing it at someone else; you are the one who gets burned"

\section{Buddha}

\footnotetext{
${ }^{1}$ PDF, Department of Psychology, Dayalbagh Educational Institute, Dayalbagh, Agra.

${ }^{2}$ Professor \& Head, Department of Psychology, Dayalbagh Educational Institute, Dayalbagh,

(C) 2015 I S Sharma, I Das; licensee IJIP. This is an Open Access Research distributed under the terms of the Creative Commons Attribution License (http://creativecommons.org/licenses/by/2.0), which permits unrestricted use, distribution, and reproduction in any Medium, provided the original work is properly cited.
} 


\section{Construction \& Standardization of Anger Scale: Validation with the help of EEG}

Anger is a natural emotion that every human being and even non-human animals experience. Anger is defined in Webster's dictionary as "a strong feeling of displeasure." Videbeck (2006) describes anger as a normal emotion that involves a strong uncomfortable and emotional response to a perceived provocation. Further it can be described as naturally occurring emotion within the repertoire of human experience. Mild forms of human anger may include displeasure, irritation or dislike. Anger arises in the mind-lake when the Gunas-Rajas and Tamas predominate. It is Rajo-Guna Vritti. Some take it as a Tamo-Guna Vritti. It is a wave of unpleasant feeling that arises from the Antahkarana, when one gets displeased with another. It was Arjuna who asked Sri Krishna: "what impels man to commit sin, O Krishna, in spite of himself and driven as it were, by force?" The blessed Lord said: "Kama esha krodha esha rojoguna-samudbhavah, Mahasano mahapapma vidhyena-miha vairinam. Dhumenavriyate vahniryathaadarso malena cha, Yathodbenavrito garbhah tatha tenedamavritam." It is desire, it is wrath, which, springs from passion. Know that it is our enemy here, a monster of greed and sin. As a flame is enveloped by smoke, as a mirror by dust, and as an unborn baby by the womb, so is this enveloped by that" (Gita: Ch. III-37\&38). Then again says Sri Krishna: "Trividham narakasyedam dwaram nasanamatmanah kamahkrodhastatha lobhastasma-detattrayam tyajet". Three are the gateways of this hell leading to the ruin of the soul-lust, wrath and greed. Therefore let man renounce these three.” Gita Ch. XVI-21. According to Frustration Aggression Hypothesis the objects of anger are perceived as a hindrance to the gratification of the desires of the angry person (Dollard, Miller, Doob, Mowrer \& Sears, 1939). Alternatively if one thinks one is superior, the result is anger. Anger is considered to be packed with more evil power than desire (Satguru Bodhinatha Veylanswami). In the Bhagavad Gita Krishna regards greed, anger, and lust as signs of ignorance and leads to perpetual bondage. As for the agitations of the bickering mind, they are divided into two divisions. The first is called avirodha-priti, or unrestricted attachment, and the other is called virodha-yukta-krodha, anger arising from frustration.

When individual reacts to frustration, criticism or a threat, individual may become angry and usually this is a healthy response. Anger may be a secondary response to feeling sad, lonely or frightened. When anger becomes a full-blown rage individual's judgment and thinking can become impaired and he/she is more likely to do and say unreasonable and irrational things. If anger is handled well it is an adaptive response to threats. Range of anger goes from mild annoyance to fury and rage. Mild anger motivates an individual to take appropriate action in many areas of life. In some cases, anger is also a strong inducement to protect oneself and loved ones when threatened. The views of Dalai Lama was reported in Urban Dharam News Shelter (2004) "anger is a destructive emotion and although anger might have some positive effects in terms of survival or moral outrage, I do not accept that anger of any kind as a virtuous emotion nor aggression as constructive behavior. Gautama Buddha has taught that there are three basic kleshas at the root of samsara (bondage, illusion) and the vicious cycle of rebirth. These are greed, hatred, and delusion - also translatable as attachment, anger, and ignorance. They bring us confusion and misery rather than peace, happiness, and fulfillment. It is in our own self- 


\section{Construction \& Standardization of Anger Scale: Validation with the help of EEG}

interest to purify and transform them”. Anger arises from frustration over internal or external events.

There are various causes of anger such as frustration, disappointment, fear, threats to personal security, feeling of powerlessness, unfulfilled expectations, being hurt by others, harassment and rejection.

When anger goes beyond an optimal level it not only causes physical harm but psychological harm also. It can create a blood sugar imbalance; it can decrease bone density, suppress the body's immune response and make it susceptible to chronic inflammation; it can suppress thyroid function, slowing down the body's metabolism; it can impair the brain's thinking ability including memory and increase blood pressure (Card, 2010). In one study of 38 boys referred for their disruptive behavior, low cortisol boys showed three times more aggressive symptoms and were judged three times more often by their peers as being the most aggressive (McBurnett, 2001). The body increases production of cortisol, which has the effect of suppressing the immune system (Moons, Eisenberger \& Taylor, 2010), and likewise there is an increase in Adrenaline levels (both cortisol and adrenaline can apparently adversely affect the cardiovascular system); thus frequently recurring or prolonged bouts of anger can result in potentially irrevocable overload and breakdown of various bodily systems. Heart disease has been linked with a competitive and anger prone personality (Mathhews, 1988, Williand, 1993). Under stress, anger prone Type 'A' people secrete more of stress hormones which suppresses disease fighting immune system (Cohen et al., 1993). Anger begets eight kinds of vices. All evil qualities and actions proceed from anger. If individual can eradicate anger, all bad qualities will die by themselves. The eight vices are; injustice, rashness, persecution, jealousy, taking possession of others' property, killing, harsh words and cruelty.

\section{DIMENSIONS OF ANGER}

Anger can be divided into three dimensions (1) Physical Expression of Anger (2) Psychological Expression of Anger (3) Social expression of Anger. Physical anger is the one in which individual causes harm to him/her. One expresses anger by keeping oneself hungry or by disturbing own sleeps hours. When anger reaches at its peak it individual may cause physical anger to self. Psychological anger is the most common anger found in individual. It is expressed through irritation and disturbed peace of mind. In the psychological expression of anger individual often become sarcastic and argumentative. Anger interrupts the decision making ability and negatively affect speech at the time of anger. When anger negatively affects the social relationships and spoils the relationship with friends and family it is the social expression of anger. Anger can be expressed in any form physical, psychological or social expression.

It is important to make a distinction between anger and aggression. Anger is an acceptable and healthy emotion, but aggression is not an acceptable method of expressing one's anger. Anger is not intended to cause harm but the motive of aggression is to cause harm and hurt the others. 


\section{Construction \& Standardization of Anger Scale: Validation with the help of EEG}

Anger is a feeling and aggression is an action. The expression of anger is acceptable but when the anger takes form of aggression it is not acceptable in the society and even not in family.

\section{NEED FOR SCALE}

As it has been already discussed that anger is a natural emotion. When anger goes beyond an optimal level it would harm individual not only physically but psychologically also. In order to measure and compare anger among individuals a need for anger scale was realized. After reviewing the literature and available scale it was found that in Indian culture, no test was available to measure anger which could fulfill the condition of the present study. Therefore, the researcher tried to construct the scale which could measure anger among individual.

\section{OBJECTIVE OF THE STUDY}

To construct and standardize a scale for measuring 'anger'.

\section{Operational Definition of Anger}

Anger is a feeling of tension and hostility, usually caused by anxiety aroused by a perceived threat to one's self, possessions, rights, or values.

\section{Steps in the Construction of the Scale}

Before selecting the items a rough draft of items was prepared according to dimensions of the anger such as (i) Psychological expression of anger, (ii) Physical expression of anger, (iii) Social expression of anger. Items related to all the dimensions were included in the rough draft.

\section{Items Selection}

The items were skillfully written in order to cover all the aspects of anger. Books and journals were consulted to prepare the items. Items were written by the investigator herself. Initially 40 items were prepared in Hindi.

\section{First Draft}

This was the crucial phase of test drafting as most of the editing work was done in this stage. Major changes were concerned with the modification of the language of the statements. There were few items which were not found suitable according to the demand of the scale were excluded from the first draft. Instructions were written for the testes,

"Below is a list of statements dealing with the general feelings. Please tick mark $(\checkmark)$ the box, in front of the statement, which most closely represents your feelings."

The most crucial task was the formation of scoring key. Scoring key was prepared on the basis of three point scale which ranged from 'most of the time' to 'rarely'. 2 score was given to 'the most of the time' 1 point was given to 'sometimes' and 0 was given to if the testee answer it as 'rarely'. Five statements were removed in the first draft because there was repetition in those items. 


\section{Construction \& Standardization of Anger Scale: Validation with the help of EEG}

\section{ITEM ANALYSIS}

Items analysis was done. Item No. 12, 16, 27, 31, 33 was found to have low coefficient of correlation with the total test scores. So these five items were removed. Thus, final draft included only 30 items.

\section{Final Draft}

In the preparation of final draft, again thorough study was done and experts' advises were incorporated. Language modification was done in 2 items. Five items were removed because their coefficient of correlation was found to be very low. Thus, final draft included only 30 items, among them 7 were related to physical expression of anger, 13 were related to psychological expression of anger and 10 were related to social expression of anger.

\section{Internal Consistency}

Table No.- 1

\begin{tabular}{|l|l|l|l|}
\hline Item & Coefficient of Correlation & Item & Coefficient of Correlation \\
\hline Item 1 & 0.57 & Item 17 & 0.61 \\
\hline Item 2 & 0.25 & Item 18 & 0.38 \\
\hline Item 3 & 0.36 & Item 19 & 0.49 \\
\hline Item 4 & 0.15 & Item 20 & 0.25 \\
\hline Item 5 & 0.15 & Item 21 & 0.41 \\
\hline Item 6 & 0.42 & Item 22 & 0.66 \\
\hline Item 9 & 0.52 & Item 23 & 0.34 \\
\hline Item 10 & 0.19 & Item 24 & 0.22 \\
\hline Item 11 & 0.33 & Item 25 & 0.56 \\
\hline Item 12 & 0.36 & Item 26 & 0.42 \\
\hline Item 13 & 0.31 & Item 27 & 0.64 \\
\hline Item 14 & 0.67 & Item 28 & 0.59 \\
\hline Item 15 & 0.22 & Item 29 & 0.41 \\
\hline Item 16 & 0.32 & Item 30 & 0.47 \\
\hline
\end{tabular}

\section{RELIABILITY}

(a) Item analysis was done to establish internal consistency of Anger Scale. Items with low coefficient of correlation ( $r=.14$ or less) with the total test scores were discarded and finally 30 items with $r=.15$ to .67 were retained in the final test.

(b) Test Retest Reliability of the scale (with a time gap of 25 days) came out to be 86 .

\section{VALIDITY}

(a) High negative coefficient of correlation of anger scores with well being indicated that higher anger leads to lower level of well being among individuals. The coefficient of correlation was found -.85. It shows the construct validity of the scale.

(b) Construct validity was indicated by significant positive relationship between egotism and 


\section{Construction \& Standardization of Anger Scale: Validation with the help of EEG}

anger also. The coefficient of correlation was .65. It shows that as the egotism increases the level of anger would also increase and vice versa.

(c) Validity of anger scale was established with the help of scores on EEG. The mean alpha wave of higher anger group was found to decrease significantly when subjects' anger was experimentally aroused. On the other hand Mean EEG scores of low anger group as measured by the Anger Scale did not change significantly. Thus, the validity of anger scale was experimentally established.

\section{NORMS}

Scores on psychological tests are most commonly interpreted by reference to norms which represent the test performance of the standardized sample. The researcher took a sample of 62 subjects from Agra. The norms of this test are established on the basis of mean and SD as well as median and quartile deviation as cut points. Thus, the scale scores are divided into four parts. Higher the score on the scale more would be the anger level. Lower the score lower will be anger level. In this manner, on the basis of median and quartile deviation along with mean and SD, the Anger scale determines the level of anger among individual (shown in Table 2).

TABLE- 2: Means, Standard Deviations, Q1, Q2 and Q3 for Anger Scale

\begin{tabular}{|c|c|c|c|}
\hline S. No & Sample & Scores & Interpretation of scores \\
\hline 1. & Above Q3 & Above 29 & Extremely High Anger \\
\hline 2. & Q2 (Mdn) to Q3 & $24-29$ & Above Average \\
\hline 3. & Median & 23 & Average \\
\hline 4. & Q1 to Below Median & $10-22$ & Low Anger \\
\hline 5. & Below Q1 & Below 10 & Extremely Low Anger \\
\hline
\end{tabular}

\section{Interpretation of Scores}

It can be said on the basis of the research of the investigator that higher scores on anger scale shows the higher anger among individual. If subject's score is above 29 then it means that subject has extremely high anger. If score is within 24-29, it shows anger level is above average. If subject's score is 23 it shows the average level of anger. If subject scores within 10-22, it means that the anger level is low and score below than 10 suggests the extremely low anger level.

\section{Implications of Anger Scale}

During college life there are many social as well as psychological changes one experiences and these changes result in frustration and aggression. This scale can be used to assess the anger level among College students. From clinical point of view, after assessing anger with this constructed 


\section{Construction \& Standardization of Anger Scale: Validation with the help of EEG}

scale one may be guided to reduce or control the anger level. In organization, this scale can be administered on employees to assess their anger level, it will give a direction to authority to control the temper of employees.

\section{REFERENCES}

Card, D. R. (2010). Anger Management Natural Remedies. Retrieved from http://www.daveshealingnotes.com/pdf/anger-natural-remedies.pdf (July 16 2015)

Dollard, J., Miller, N.E., Doob, L.W., Mowrer, O.H. \& Sears, R H. (1939). "FRUSTRATION AND AGGRESSION”. New Haven, Conn: Yale University.

McBurnett, K., Lahey, B. Rathouz, P \& Loeber, R. 2001. "Low salivary cortisol and persistent aggression in boys referred for disruptive behavior.” Archives of General Psychiatry, Vol. 58. Pages 513 to 515.

Moons, W. G., Eisenberger, N. I., \& Taylor, S. E. (2010). “Anger and fear responses to stress have different biological profiles.” Brain, Behavior, and Immunity, Vol. 24, Pages 215 to 219.

Myers, D G. (1996). “Social Cognition \& Human Well being.” Social Psychology. New York : McGraw Hill Companies.

The Urban Dharma Newsletter (2004). Retrieved from http://en.wikipedia.org/wiki/Anger (July 16 2015).

Videbeck, Sheila L. (2006). “PSYCHIATRIC MENTAL HEALTH NURSING” (3rd ed.). Lippincott Williams \& Wilkins. 